\title{
Correspondance
}

\section{Challenges of teaching EBM}

A $s$ a clinician at an academic institution and possessor of a master's degree in clinical epidemiology, I support the principles of evidencebased medicine (EBM). Nevertheless, I have found it a challenge to teach $\mathrm{EBM}$, primarily because it is a significant challenge to practise EBM. The series by Peter Wyer and associates, ${ }^{1}$ especially the "tips for teachers" components, will go a long way toward assisting in the instruction of EBM, but unless trainees can use EBM practically and witness their teachers using it practically, we will not achieve the goal of EBM becoming a core competency of the next generation of physicians.

Part 1 in the series is an example. ${ }^{2}$ Using tip 2 ("Balancing benefits and adverse effects in individual patients") requires information on the background risk. This in turn requires efficient access to the types of information cited in the article. ${ }^{3,4}$ Efficient and effective access to that kind of information in most settings - either the over-busy hospital ward or the private office - is a challenge. (Ease of access is not a problem, because of ubiquitous Internet connectivity and the plethora of databases.)

In some areas of practice (particularly cardiovascular disease and cancer) information is available to feed into EBM approaches, such as the results of randomized controlled trials, background risks and other epidemiologic data. In other specialty fields, however, such as pediatrics, those data do not exist. In generalist fields such as family medicine the problem is the huge variety of patients and the constant shift from simple to complex conditions across age groups.

Two factors have hindered adoption of EBM: the challenge of teaching this material and the challenge of applying it. This series will (hopefully) help to address the former, but we have not done enough about the latter.

\section{Hal Siden}

Clinical Associate Professor

Department of Pediatrics

University of British Columbia

Vancouver, BC

\section{References}

1. Wyer PC, Keitz S, Hatala R, Hayward R, Barratt A, Montori V, et al. Tips for learning and teaching evidence-based medicine: introduction to the series [editorial]. CMA7 2004;171(4):347-8.

2. Barratt A, Wyer PC, Hatala R, McGinn T, Dans AL, Keitz S, et al, for the Evidence-Based Medicine Teaching Tips Working Group. Tips for learners of evidence-based medicine: 1 . Relative risk reduction, absolute risk reduction and number needed to treat. CMA7 2004;171(4):353-8

3. SHEP Cooperative Research Group. Prevention of stroke by anti-hypertensive drug treatment in older persons with isolated systolic hypertension. Final results of the Systolic Hypertension in the Elderly Program (SHEP). FAMA 1991;265: 3255-64.

4. SALT Collaborative Group. Swedish Aspirin Low-dose Trial (SALT) of $75 \mathrm{mg}$ aspirin as secondary prophylaxis after cerebrovascular events. Lancet 1991:338:1345-9.

DOI:10.1503/cmaj.1041600

Tam just finishing a master's degree in medical education, and my thesis work is closely related to the series on learning and teaching EBM. ${ }^{1}$ I have used the name DIETS (for "Disease management Interactive Teaching
Script") for my system, which incorporates up-to-date EBM in teaching the management of chronic disease to primary care doctors and nurses. The DIETS system includes presentations on topics such as hypertension and diabetes, which take the form of minilessons or "slide sets." In contrast to the teaching tips articles, ${ }^{2}$ which a reader can dip into and out of, each DIETS talk must be presented in its entirety, as a reflection of the longitudinal nature of primary care. Another difference is that feedback in DIETS is formalized, appearing in the third slide of each set, whereas feedback is less structured in the teaching tips. An important similarity between the scripts used in the DIETS system and those in the EBM series is that the teaching of particular points conforms with the suggestions of Peile and colleagues, ${ }^{3}$ who discussed the notion of threshold concepts - key concepts that, once understood, allow learners to understand, interpret or view something in a different way. Until that threshold is crossed, the student will struggle to progress.

I have used part 1 of the teaching tips series ${ }^{2}$ to analyze the synopsis ${ }^{4}$ (published recently in $C M A 7$ ) of the

\section{Mécanisme de présentation des lettres}

Le site amélioré des cyberlettres du JAMC est désormais le portail de réception de tous les textes destinés à la chronique Lettres. Pour rédiger une cyberlettre, consultez un article sur le site www.jamc.ca et cliquez ensuite sur le lien «Lettres électroniques : répondre à cet article», dans la boîte en haut à droite de l'article. Toutes les cyberlettres seront étudiées pour une éventuelle publication dans le journal imprimé.

Les lettres répondant à un article publié dans le JAMC sont plus susceptibles d'être acceptées pour publication imprimée si elles sont présentées dans les deux mois de la date de publication de l'article. Les lettres acceptées pour publication imprimée sont révisées en fonction du style du JAMC et raccourcies au besoin (elles doivent habituellement compter au maximum 250 mots). 
Collaborative Atorvastatin Diabetes Study (CARDS) and can suggest 2 additional exercises related to this study. First, in CARDS, the reduction in the death rate for diabetic patients who received atorvastatin was from $5.8 \%$ to $4.3 \%$, an absolute risk reduction of $1.5 \%$ over 4 years $(1.5 \% / 4=0.375 \%$ annually), which yields a number needed to treat of $100 / 0.375$ or about 275 . If atorvastatin costs about $£ 20$ per month (about Can\$47), how much did it cost to save one life? The answer is $20 \times 12 \times 275$ or $£ 66000$ (Can\$154 500). Is this cost-effective? Second, from the CARDS data, we can calculate the 10-year risk of coronary artery disease for diabetic patients not receiving statin treatment. The overall rate of cardiovascular events in the placebo group was $13.4 \%$, and median follow-up was 4 years. Therefore, the annual rate would be $13.4 \% / 4(3.35 \%)$ and the 10 -year rate would be $33.5 \%$. The rate of coronary artery disease was approximately three-quarters of the total cardiovascular risk ${ }^{5,6}$ or about $25 \%$.

\section{Gerry E. Burns}

Family Doctor

National Health Service

Belfast, Northern Ireland

\section{References}

1. Wyer PC, Keitz S, Hatala R, Hayward R, Barratt A, Montori V, et al. Tips for learning and teaching evidence-based medicine: introduction to the series [editorial]. CMA7 2004:171(4):347-8.

2. Barratt A, Wyer PC, Hatala R, McGinn T, Dans AL, Keitz S, et al, for the Evidence-Based Medicine Teaching Tips Working Group. Tips for teachers of evidence-based medicine: 1 . Relative risk reduction, absolute risk reduction and number needed to treat [online]. CMA7 2004;171(4): Online-1-8. Available: www.cmaj.ca/cgi/data /171/4/353/DC1/1 (accessed 2004 Nov 18).

3. Peile E, Macdougall C, McCarthy L. What the educators are saying. BM7 2004;328:692.

4. Hackam DG. Should a statin be routinely prescribed for primary prevention of cardiovascular disease in diabetes mellitus? CMAf 2004;171(8): 857.

5. Wallis EJ, Ramsay LE, UI Haq I, Ghahramani P, Jackson PR, Rowland-Yeo K, et al. Coronary and cardiovascular risk estimation for primary prevention: validation of a new Sheffield table in the 1995 Scottish health survey population. BMF 2000;320:671-6.

6. Ramsay LE, Williams B, Johnston GD, MacGregor GA, Poston L, Potter JF, et al. British Hypertension Society guidelines for hypertension management 1999: summary. BMF 1999; 319:630-5.

DOI:10.1503/cmaj.1041708

\section{[Three of the authors respond:]}

W e thank Harold Siden and Gerry Burns for sharing their insights regarding the challenges of teaching EBM to clinicians and for raising important issues pertaining to the use of tips (or scripts) and other fascinating innovations in such teaching. Siden points more broadly to obstacles to the full integration of EBM into clinical practice. We have addressed Gerry Burns's comments regarding number needed to treat, cost-effectiveness and long-term outcomes in a previous letter. ${ }^{1}$

Burns suggests a relationship, and some potential differences, between our EBM scripts, ${ }^{2}$ his own scripts and the notion of "threshold concepts" being developed within the ETL project (Enhancing Teaching-Learning Environments in Undergraduate Courses) at the University of Edinburgh (www.ed .ac.uk/etl/project.html). We suspect that the improvisational aspect of our scripts may constitute one important difference. Our scripts, like those studied by Irby, ${ }^{3,4}$ are subject to variation, truncation and expansion, depending on the circumstances and on learners' prior knowledge. Irby described how exemplary clinical teachers balance illness and curriculum scripts in the course of customizing their teaching rounds to the needs of both patients and learners. ${ }^{3}$ Rather than threshold concepts, he focused on characteristic learner misconceptions as guides to instructional decisions.

We find interactive teaching to be inherently improvisational. In the teachers' versions of our tips, ${ }^{5}$ narrative descriptions highlight possible variations based on learners' responses and characteristic errors. The reports of field tests describe substantive modifications of the approaches that have arisen when teachers not involved in developing the tips used them in learner settings different from those in which they originated.

Both Siden and Burns touch on the need to adapt the tips to specific contexts by using examples and corresponding numbers relevant to the topic or question at hand. Readers of both the learners' $^{6}$ and the teachers ${ }^{\prime 5}$ versions of a sin- gle tips installment, such as installment 2 on confidence intervals, may notice that a given example is presented more generically in the latter than in the former. We expect that teachers who adopt these approaches will frequently supply their own clinical context, numbers drawn from an article being appraised or other specialty-specific content.

Siden comments on variations in availability of quality evidence among different medical specialties and clinical areas. Resources such as the ACP fournal $C l u b$ place internal medicine in advance of many other specialties in important clinical areas. Efforts aimed at a broader range of specialties exist, such as the McMaster Online Rating of Evidence ("MORE"; see http://hiru.mcmaster .ca/more). A paucity of clinical research ultimately limits evidence-based clinical practice. Undoubtedly, the frontiers of medical knowledge based upon wellperformed clinical research will continue to expand over time, rendering all the more salient the need for effective teaching tools in equipping clinicians to digest and use such information.

\section{Peter C. Wyer}

Columbia University College of

Physicians and Surgeons

New York, NY

\section{Rose Hatala}

Department of Medicine

University of British Columbia

Vancouver, BC

Gordon Guyatt

Departments of Medicine and of Clinical

Epidemiology and Biostatistics

McMaster University

Hamilton, Ont.

\section{References}

1. Barratt AL, Wyer PC, Guyatt G, Simpson JM. NNT for studies with long-term follow-up [letter]. CMA7 2005;172(5):613-5.

2. Wyer PC, Keitz S, Hatala R, Hayward R, Barratt A, Montori V, et al. Tips for learning and teaching evidence-based medicine: introduction to the series [editorial]. CMA7 2004;171(4):347-8.

3. Irby DM. How attending physicians make instructional decisions when conducting teaching rounds. Acad Med 1992;67:630-8.

4. Irby DM. What clinical teachers in medicine need to know. Acad Med 1994;69:333-42.

5. Montori VM, Kleinbart J, Newman TB, Keitz S, Wyer PC, Guyatt G. Tips for teachers of evidence-based medicine: 2 . Confidence intervals and $p$ values [online]. CMAF 2004;171(6):Online-1-12. Available: www.cmaj.ca/cgi/data /171/6/611/DC1/1 (accessed 2005 Apr 14). 